\title{
Effectiveness of pollutants removal in hybrid constructed wetlands - different configurations case study
}

\author{
Magdalena Gajewska ${ }^{1}$, Krzysztof Jóźwiakowski ${ }^{2}$, and Katarzyna Skrzypiec ${ }^{1, *}$ \\ ${ }^{1}$ Gdańsk University of Technology, Faculty of Civil and Environmental Engineering, Narutowicza St. \\ 11/12, 80-233, Gdańsk, Poland (mgaj@pg.gda.pl, katskrzy1@student.pg.gda.pl) \\ ${ }^{2}$ University of Life Sciences in Lublin, Faculty of Production Engineering, Akademicka St. 13, \\ 20-950, Lublin, Poland (krzysztof.jozwiakowski@up.lublin.pl)
}

\begin{abstract}
In recent years, an increase in interest in hybrid constructed wetland systems (HCWs) has been observed. The aim of the paper is to compare different $\mathrm{HCW}$ configurations in terms of mass removal rates and efficiency of pollutants removal. Analysed data have been collected at multistage constructed wetlands in Poland, which are composed by at least two beds: horizontal subsurface flow (SSHF) and vertical subsurface flow (SSVF). The evaluation was focused on hybrid constructed wetlands performance with $\mathrm{HF}+\mathrm{VF}$ vs. $\mathrm{VF}+\mathrm{HF}$ configuration, where influent wastewater of the same composition was treated. In analysed HCWs, the effective removal of organic matter from 75.2 to $91.6 \%$ COD was confirmed. Efficiency of total nitrogen removal varied from 47.3 to $91.7 \%$. The most effective removal of TN $\left(8.3 \mathrm{~g} \mathrm{~m}^{-2} \mathrm{~d}^{-1}\right)$ occurred in the system with $\mathrm{VF}+\mathrm{VF}+\mathrm{HF}$ configuration.
\end{abstract}

\section{Introduction}

Constructed wetlands (CWs) for wastewater treatment have been met with great interest during the past decades because of their performances, low investment and operational costs and positive effect on the environment. Subsurface CW systems are composed of filters with different modes of sewage flow: SS VF - vertical or SS HF - horizontal. Hybrid constructed wetlands combine the benefits of both types of beds, thus proving to achieve higher efficiency of pollutants removal, especially nitrogen compounds. These systems consist of two or more VF and HF filters, both types of beds have different working conditions and ensure different character of the processes. In vertical flow CW the dominating processes are organic matter mineralisation and ammonia nitrification due to better oxygen conditions in comparison with the horizontal flow $\mathrm{CW}$, with claims of better final effluent quality (lower organic matter concentration, complete nitrification and partial denitrification) [1-6].

The pathways for nitrogen transformation in subsurface flow wetlands are complex and diverse, and include ammonification, sorption, plant and microbial uptake, ammonia

*Corresponding author: katskrzy1@student.pg.gda.pl 
volatilization, nitrification, and denitrification. The prevailing processes differ in magnitude depending on the design and mode of operation. In general, SSVF wetlands are unsaturated units usually fed intermittently, resulting in high oxygen transfer capacity, thus favouring the nitrification process within the wetland bed. On the other hand, SSHF wetlands operate mostly under anoxic/anaerobic conditions due to the permanent saturation of the bed, which makes it a likely environment for denitrification. SSHF beds are also responsible for effective suspended solids and organic matter removal $[4,5,7]$.

The objective of the paper is to evaluate performance of hybrid constructed wetlands with different configurations of the beds in respect of pollutants removal efficiency and MRR (mass removal rate) after each stage of treatment. Very unique results from the HCW built to treat domestic wastewater were obtained, in which the discharged wastewater was split into two streams treated in two configurations, enabling for reliable estimation.

\section{Materials and methods}

The investigations were carried out at five constructed wetlands in Poland: two for single family (SF TWs) in Dąbrowica I and Dąbrowica II, southeast part of the country, two for the local community (local TWs) in Darżlubie and Wiklino, located in Pomerania region, and one for reject water treatment from digested sludge dewatering in centrifuge at an existing activated sludge plant (Pilot Wschód RWC).

The analysed MTWs differ from one another in the order and number of subsequent stages. The characteristic of the systems with configuration of the beds is given in Table 1 .

Table 1. The operation conditions of the MTWs.

\begin{tabular}{|c|c|c|c|c|}
\hline Plant, location and type & $\begin{array}{c}\text { Flow } \\
{\left[\mathrm{m}^{3} \text { day }^{-1}\right]} \\
\text { (pe) }\end{array}$ & Configuration & $\begin{array}{l}\text { Area } \\
{\left[\mathrm{m}^{2}\right]}\end{array}$ & $\begin{array}{c}\text { Hydraulic } \\
\text { load } \\
{\left[\mathrm{mm} \mathrm{day}^{-1}\right]}\end{array}$ \\
\hline Darżlubie, Poland, local TW & $\begin{array}{l}56.6 ; \\
(650)\end{array}$ & $\begin{array}{c}\text { SSHF I } \\
\text { Cascade bed } \\
\text { SSHF II } \\
\text { SSVF } \\
\text { SSHF III }\end{array}$ & $\begin{array}{c}1200 \\
400 \\
500 \\
250 \\
1000 \\
\Sigma 3350\end{array}$ & $\begin{array}{c}47.3 \\
141.2 \\
113.4 \\
113.4 \\
56.7\end{array}$ \\
\hline Wiklino, Poland, local TW & $\begin{array}{l}18.6 ; \\
(220)\end{array}$ & $\begin{array}{l}\text { SSHF I } \\
\text { SSVF } \\
\text { SSHF II }\end{array}$ & $\begin{array}{c}1050 \\
624 \\
540 \\
\Sigma 2214\end{array}$ & $\begin{array}{l}19.5 \\
65.7 \\
38.0\end{array}$ \\
\hline Pilot Wschód, Poland, RWC & $\begin{array}{c}0.24 \\
(5)\end{array}$ & $\begin{array}{c}\text { SSVF I } \\
\text { SSVF II } \\
\text { SSHF }\end{array}$ & $\begin{array}{c}7.5 \\
5.0 \\
3.9 \\
\Sigma 16.4\end{array}$ & $\begin{array}{c}3.2 \\
4.8 \\
28.5\end{array}$ \\
\hline Dąbrowica I, Poland, SF TW & $\begin{array}{l}0.3 \text {; } \\
(3)\end{array}$ & $\begin{array}{l}\text { SSHF } \\
\text { SSVF }\end{array}$ & $\begin{array}{c}24 \\
24 \\
\Sigma 48\end{array}$ & 12.0 \\
\hline Dąbrowica II, Poland, SF TW & $\begin{array}{l}0.3 \text {; } \\
\text { (3) }\end{array}$ & $\begin{array}{l}\text { SSVF } \\
\text { SSHF }\end{array}$ & $\begin{array}{c}24 \\
24 \\
\Sigma 48\end{array}$ & 12.0 \\
\hline
\end{tabular}

At local TWs, configuration with first stage HF bed was applied. In case of Darżlubie facility, second stage filter was divided into two parallel beds working continuously while at Wiklino VF beds worked alternately with two weeks resting periods. The configuration performance with SSVF beds working as a first stage followed by SSHF was based on results achieved in Pilot Wschód RWC. The results for this configuration were compared 
with those achieved in Waizenfeld hybrid constructed wetland near Nuernberg of the same configuration (described in [3]). In case of SF TWs, opposite bed configurations used in these two systems $(\mathrm{HF}+\mathrm{VF}$ vs. $\mathrm{VF}+\mathrm{HF})$ were very valuable for comparison of treatment efficiency due to the identical dimensions of the beds and the same composition of influent wastewater $[2,3]$.

Averaged samples of influent, effluent and after subsequent stages of treatment in all systems were analysed. In order to evaluate the removal efficiencies, the following parameters were measured: organic matter (COD), total nitrogen (TN), ammonium nitrogen $\left(\mathrm{N}-\mathrm{NH}_{4}{ }^{+}\right)$, nitrate nitrogen $\left(\mathrm{N}_{-} \mathrm{NO}_{3}{ }^{-}\right)$, according to the methods of Polish Standards in accordance with the standard methods (APHA 2005) [8,9]. Removal efficiency was calculated as a quotient of contaminants concentration difference in influent and effluent after subsequent stages of constructed wetland and concentration in influent. Mass removal rate (MRR) was calculated on the basis of the following equation:

$$
M R R=\left(C_{\text {in }} \cdot Q_{\text {in }}-C_{\text {out }} \cdot Q_{\text {out }}\right) / A\left[\mathrm{~g} \mathrm{~m}^{-2} \mathrm{~d}^{-1}\right]
$$

$A$ is the area of MTW $\left[\mathrm{m}^{2}\right], Q_{\text {in }}$ and $Q_{\text {out }}$ are the average influent and effluent flow rates, respectively $\left[\mathrm{m}^{3} \mathrm{~d}^{-1}\right], C_{\text {in }}$ and $C_{\text {out }}$ are average influent and effluent pollutant concentrations, respectively $\left[\mathrm{mg} \mathrm{L}^{-1}\right]$.

In case of Darżlubie and Wiklino, combined spot samples were taken monthly at each stage of the HCWs from 1998 to 2006. Data from Pilot Wschód RWC was collected in 2010 and from HCW systems in Dąbrowica I and Dąbrowica II in 2007-2010 [2, 10].

\section{Results and discussion}

Treatment efficiency depends on many factors, among other such as susceptibility of wastewater to biodegradation, hydraulic load and organic load. In the analysed MTWs, the quality of discharged wastewater was unstable in time and varied significantly for both nitrogen and organic compounds (Table 2). An assessment of wastewater biodegradability is most often based on $\mathrm{COD} / \mathrm{BOD}_{5}$ ratio, and when effective nitrogen removal is required the $\mathrm{BOD}_{5} /$ total nitrogen $(\mathrm{TN})$ ratio is considered $[4,10,11]$.

Table 2. The quality of influent wastewater and biodegradability of wastewater in analysed MTWs.

\begin{tabular}{|c|c|c|c|c|c|}
\hline Plant & $\begin{array}{l}\mathrm{TN} \\
{\left[\mathrm{mg} \mathrm{N} \mathrm{L}^{-1}\right]} \\
\operatorname{mean} \pm \sigma \\
\min \div \max \end{array}$ & $\begin{array}{l}\mathrm{COD} \\
{\left[\mathrm{mg} \mathrm{O}_{2} \mathrm{~L}^{-1}\right]} \\
\text { mean } \pm \sigma \\
\min \div \max \end{array}$ & $\begin{array}{l}\mathrm{BOD}_{5} \\
{\left[\mathrm{mg} \mathrm{O}_{2} \mathrm{~L}^{-1}\right]} \\
\text { mean } \pm \sigma \\
\min \div \max \end{array}$ & $\begin{array}{l}\mathrm{COD} / \mathrm{BOD}_{5} \\
{[-]} \\
\text { mean }\end{array}$ & $\begin{array}{l}\mathrm{BOD}_{5} / \mathrm{TN} \\
{[-]} \\
\text { mean }\end{array}$ \\
\hline \multirow[t]{2}{*}{ Darżlubie } & $120.8 \pm 4.3$ & $843.8 \pm 40.7$ & $368.7 \pm 16.0$ & \multirow[t]{2}{*}{2.4} & \multirow[t]{2}{*}{3.1} \\
\hline & $114.3 \div 128.9$ & $791.4 \div 901.5$ & $340.2 \div 390.5$ & & \\
\hline \multirow[t]{2}{*}{ Wiklino } & $130.4 \pm 9.2$ & $714.6 \pm 110.7$ & $382.1 \pm 72.0$ & \multirow[t]{2}{*}{1.9} & \multirow[t]{2}{*}{3.4} \\
\hline & $118.4 \div 148.0$ & $508.8 \div 932.5$ & $280.6 \div 500.7$ & & \\
\hline \multirow[t]{2}{*}{ Pilot Wschód RWC } & $788.1 \pm 170.9$ & $1022.7 \pm 93.5$ & $378.9 \pm 87.0$ & \multirow[t]{2}{*}{2.7} & \multirow[t]{2}{*}{0.5} \\
\hline & $710.4 \div 1789.2$ & $880.0 \div 1260.0$ & $270.8 \div 569.0$ & & \\
\hline \multirow[t]{2}{*}{ Dąbrowica I } & $134.0 \pm 25.4$ & $408.0 \pm 94.2$ & $169.0 \pm 65.9$ & \multirow[t]{2}{*}{2.4} & \multirow[t]{2}{*}{1.3} \\
\hline & $109.0 \div 201.0$ & $68.0 \div 300.0$ & $99.0 \div 338.0$ & & \\
\hline \multirow[t]{2}{*}{ Dąbrowica II } & $134.0 \pm 25.4$ & $408.0 \pm 94.2$ & $169.0 \pm 65.9$ & \multirow[t]{2}{*}{2.4} & \multirow[t]{2}{*}{1.3} \\
\hline & $109.0 \div 201.0$ & $68.0 \div 300.0$ & $99.0 \div 338.0$ & & \\
\hline
\end{tabular}

Only in one HCW, wastewater is characterised by COD/BOD5 below 2 and can be assumed as easily degradable and good source of electron donors for nitrogen removal in denitrification process. In case of reject water, the BOD5/TN ratios were far from recommended value, usually much smaller, showing a very high concentration of nitrogen in comparison to the available easily degradable organic matter. 
Organic load applied in Darżlubie facility was the highest and amounted to $39.0 \mathrm{~g}$ COD $\mathrm{m}^{-2}$ day $^{-1}$ while in Wiklino $\mathrm{HCW}$ it was three times lower. For HCW treating reject water this parameter was $22.8 \mathrm{~g} \mathrm{COD} \mathrm{m}^{-2} \mathrm{day}^{-1}$. The lowest organic matter loading rate (7.0 $\mathrm{g} \mathrm{COD} \mathrm{m}^{-2}$ day $^{-1}$ ) occurred in the smallest SF TWs.

Considerably high hydraulic load was used for local TWs, with the highest values in Darżlubie. In the Pilot Wschód facility the lowest hydraulic load was applied (3.2 mm day ${ }^{-1}$ on the first SSVF bed). Hydraulic load in all systems does not exceed the recommended value of $300 \mathrm{~mm}^{-1} \mathrm{day}^{-1}[4,12]$.

Pollutants concentrations in wastewater in analysed hybrid constructed wetlands are higher than the most commonly occurring in other European countries. The quality of influent wastewater is comparable with raw wastewater without pretreatment (France) $[2,6,7,12,13]$.

\subsection{HF + VF configuration}

Based on removed loads of pollutants, mass removal rates from each stage of treatment in analysed HCWs were calculated and presented in Table 3.

Table. 3. Mass removal rates (MRR, $\mathrm{g} \mathrm{m}^{-2} \mathrm{~d}^{-1}$ ) in local TWs.

\begin{tabular}{ccccccc}
\hline Plant & Configuration & COD & TN & ${\mathrm{N}-\mathrm{NH}_{4}{ }^{+}}_{5}$ & $\mathrm{~N}_{\text {org }}$ & ${\mathrm{N}-\mathrm{NO}_{3}}^{-}$ \\
\hline & SSHF I & 20.6 & 3.4 & 3.6 & +++ & +++ \\
& Cascade bed & 18.0 & 2.9 & 2.2 & 1.2 & +++ \\
Darżlubie & SSHF II & 7.0 & 0.8 & 0.4 & 0.1 & 0.3 \\
& SSVF & 10.8 & 0.7 & 1.4 & 0.3 & +++ \\
& SSHF III & 5.7 & 0.5 & 0.2 & 0.1 & 0.2 \\
& Total & 13.1 & 1.9 & 1.8 & 0.1 & 0.0 \\
\hline \multirow{5}{*}{ Wiklino } & SSHF I & 6.9 & 1.1 & 1.1 & 0.0 & 0.9 \\
& SSVF & 5.0 & 0.6 & 0.5 & 0.5 & +++ \\
& SSHF II & 2.5 & 0.8 & 0.5 & 0.3 & 0.0 \\
& Total & 5.3 & 0.9 & 0.8 & 0.2 & 0.0 \\
\hline
\end{tabular}

+++ - an increase of pollutant parameter occurred

The highest COD and TN removal rates were noticed in first stage SSHF beds. In case of SSVF beds, MRR values were lower for organic matter (10.8 and $5.0 \mathrm{~g} \mathrm{COD} \mathrm{m}^{-2} \mathrm{~d}^{-1}$, respectively) and total nitrogen $\left(0.7\right.$ and $0.6 \mathrm{~g} \mathrm{TN} \mathrm{m}^{-2} \mathrm{~d}^{-1}$, respectively). System in Darżlubie was characterized by higher average removal rates of almost all pollutants (13.1 $\mathrm{g} \mathrm{COD} \mathrm{m}^{-2} \mathrm{~d}^{-1}, 1.9 \mathrm{~g} \mathrm{TN} \mathrm{m}^{-2} \mathrm{~d}^{-1}$ ) while in Wiklino facility such effects were not noted. An important issue appeared in relation to the removal of nitrate nitrogen as concentrations of $\mathrm{N}^{-\mathrm{NO}_{3}}{ }^{-}$increased in local TW systems, especially after SSVF beds.

Pollutants removal efficiency in analysed HCWs is presented in Fig. 1.

Analysed HTWs were characterized by very effective organic matter removal, with $88.2 \%$ in Wiklino and $91.6 \%$ in Darżlubie. The highest TN removal was observed in Darżlubie (91.7\%). Achieved results are similar to data described previously in [14, 6, 15, 16]. During measurement period facilities worked with various effectiveness of nitrogen removal. In HF beds TN was removed with higher effectiveness in comparison with VF beds. Removal efficiency of $\mathrm{N}^{-\mathrm{NH}_{4}}{ }^{+}$in all the treatment stages were usually much higher compared to total nitrogen removal. 

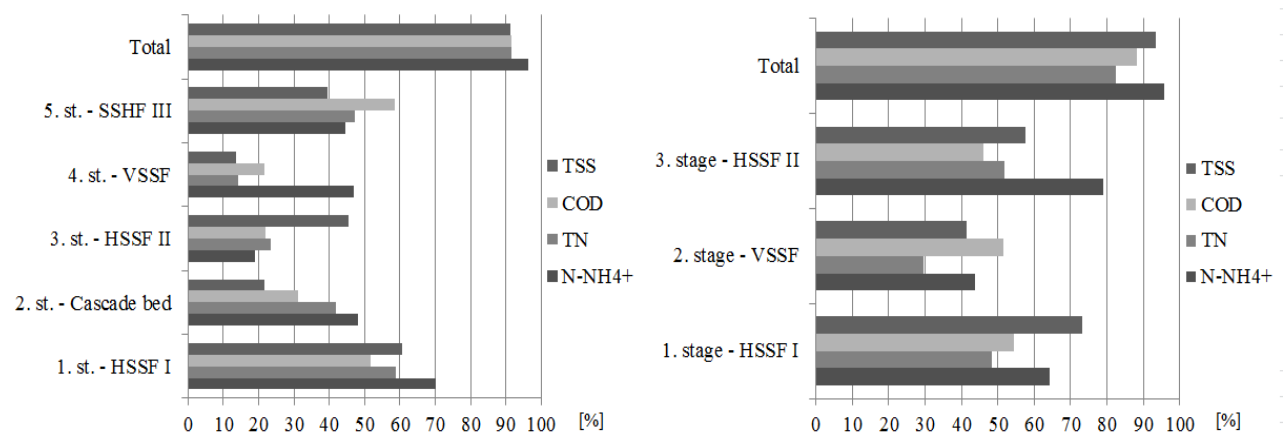

Fig. 1. Removal effectiveness of pollutants - Darżlubie (on the left) and Wiklino (on the right).

\subsection{VF + HF configuration}

Configuration with VF+HF was applied at pilot wetland system for reject water treatment. In Table 4 mass removal rates for subsequent beds of the analysed facility are given.

Table. 4. Mass removal rates (MRR, $\mathrm{m}^{-2} \mathrm{~d}^{-1}$ ) in Pilot Wschód RWC.

\begin{tabular}{cccccc} 
& COD & $\mathrm{TN}$ & $\mathrm{N}-\mathrm{NH}_{4}{ }^{+}$ & $\mathrm{N}_{\text {org }}$ & ${\mathrm{N}-\mathrm{NO}_{3}}^{-}$ \\
\hline VSSF I & 12.7 & 8.3 & 8.4 & 0.3 & +++ \\
VSSF II & 6.8 & 5.5 & 5.5 & 0.7 & +++ \\
HSSF & 12.2 & 6.1 & 5.2 & 0.4 & 0.1 \\
Total & 10.8 & 7.0 & 6.8 & 0.4 & 0.0 \\
\hline
\end{tabular}

+++ - an increase of pollutant parameter occurred

Average mass removal rate of total nitrogen was significant high and confirmed effective removal $\left(7.0 \mathrm{~g} \mathrm{~m}^{-2} \mathrm{~d}^{-1}\right)$. Organic matter removal rate in the $\mathrm{CW}$ system may be considered satisfactory $\left(10.8 \mathrm{~g} \mathrm{~m}^{-2} \mathrm{~d}^{-1}\right)$.

Achieved results in analysed HCW were compared with those from HCW located in Waizenfeld, Germany (Table 5). In respect of ammonium nitrogen removal, more efficient nitrification process took place at polish facility and amounted to $8.4 \mathrm{~g} \mathrm{~N} \mathrm{~m}^{-2}$ day $^{-1}$, while in Waizenfeld the highest removal rate was $3.6 \mathrm{~g} \mathrm{~N} \mathrm{~m}^{-2}$ day ${ }^{-1}$, both results were achieved in VSSF beds.

Table 5. The average contamination removal rates $\left(\mathrm{g} \mathrm{m}^{-2} \mathrm{day}^{-1}\right)$ in HCW in Germany [3].

\begin{tabular}{cccc}
\hline \multirow{2}{*}{ Configuration } & COD & TN & $\mathrm{N}^{-} \mathrm{NH}_{4}^{+}$ \\
\cline { 2 - 4 } & \multicolumn{3}{c}{ Waizenfeld } \\
\hline VSSF & 35.0 & 2.7 & 3.6 \\
HSSF & 0.54 & 0.68 & 0.21 \\
Total & 23.6 & 2.05 & 2.52 \\
\hline
\end{tabular}

Configuration $\mathrm{VF}+\mathrm{HF}$ created favourable conditions for nitrification process and effective removal of organic compounds, whilst in Waizenfeld total nitrogen was not so effectively removed as it could be expected. Based on data collected at Pilot Wschód RWC, effectiveness of performance was calculated and presented in Fig. 2. 


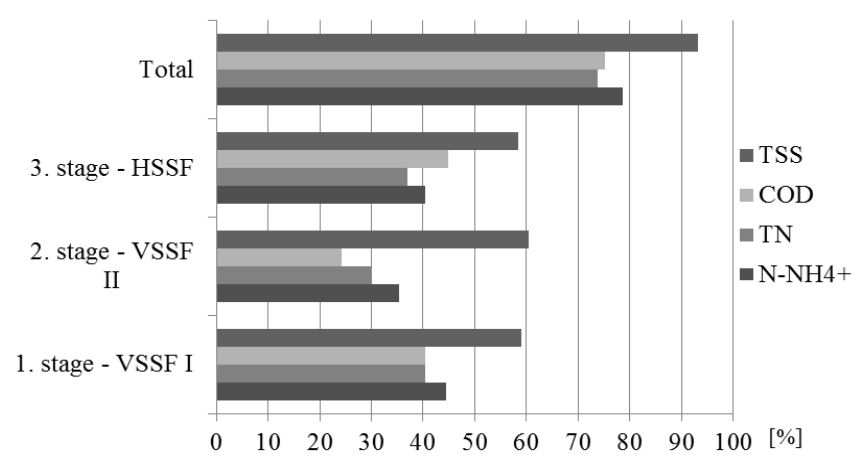

Fig. 2. Removal effectiveness of pollutants - Pilot Wschód RWC.

Total nitrogen removal was higher at Pilot Wschód in comparison with the German $\mathrm{CW}$, where TN was removed with efficiency of $64.2 \%$. On the other hand, the Waizenfeld hybrid constructed wetland was $96.7 \%$ efficient in ammonium removal while in polish $\mathrm{HCW}$ the efficiency of $\mathrm{N}-\mathrm{NH}_{4}{ }^{+}$removal was much lower (78.6\%). In Waizenfeld the most efficient removal processes took place in VF bed situated at the first stage of treatment, and HF bed played less important role.

\subsection{HF + VF vs. VF + HF configuration - comparison}

SF TWs in Dąbrowica I and Dąbrowica II were fed with domestic wastewater of the same composition which allowed for comparison of the effectiveness of the HF+VF and VF + HF configurations. Calculated MRR are presented in Table 6.

Table. 6. Mass removal rates (MRR, $\mathrm{g} \mathrm{m}^{-2} \mathrm{~d}^{-1}$ ) in SF TWs.

\begin{tabular}{ccccc}
\hline Plant & Configuration & BOD $_{5}$ & COD & TN \\
\hline \multirow{3}{*}{ Dąbrowica I } & HSSF & 1.3 & 2.9 & 0.2 \\
& VSSF & 0.7 & 1.6 & 0.6 \\
& Total & 1.0 & 2.3 & 0.4 \\
\hline \multirow{3}{*}{ Dąbrowica II } & VSSF & 1.9 & 4.4 & 0.8 \\
& HSSF & 0.1 & 0.2 & 0.2 \\
& Total & 1.0 & 2.3 & 0.5 \\
\hline
\end{tabular}

Analysed systems achieved satisfactory and equal total removal rates for organic matter expressed as $\mathrm{BOD}_{5}$ and $\mathrm{COD}$, although comparing subsequent stages in each system, first stage of treatment performed more effectively than the second one. TN removal in SSHF filters in both HCWs amounted to $0.2 \mathrm{~g} \mathrm{~m}^{-2} \mathrm{~d}^{-1}$. Higher removal rates were achieved in SSVF beds $\left(0.6 \mathrm{~g} \mathrm{~m}^{-2} \mathrm{~d}^{-1}\right.$ in the filter working as second stage and $0.8 \mathrm{~g} \mathrm{~m}^{-2} \mathrm{~d}^{-1}$ in configuration as first stage).

In Fig. 3 pollutants removal efficiency of each stage in $\mathrm{VF}+\mathrm{HF}$ and $\mathrm{HF}+\mathrm{VF}$ configuration is shown.

Overall COD removal efficiency was very similar (around 90\%). In VF beds, nitrogen compounds were removed with much higher efficacy compared to the HF beds. Performance of VF bed when applied as first stage is characterised by higher removal rates of all pollutants. Thus configuration with VF bed at the beginning of the system has significant impact on TN removal. Comparing horizontal flow beds working in different configurations, it was noted that second stage SSHF bed creates unfavourable conditions for nutrients removal, as effectiveness for TN did not exceed $25 \%$. It can be associated with insufficient content of organic matter e.g. for denitrification process. 

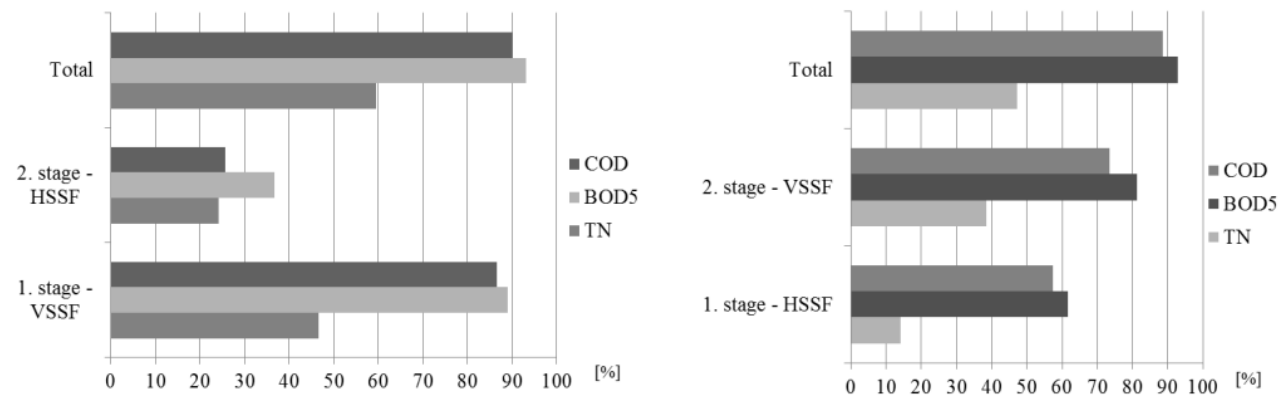

Fig. 3. Removal efficiency - Dąbrowica I (on the right) and Dąbrowica II (on the left).

\section{Conclusions}

Based on carried out analyses of efficiency removal and mass removal rate for each stage of treatment in hybrid constructed wetlands it could be concluded:

1. Hybrid constructed wetlands ensure stable in time removal of organics (up to $90 \%$ ) and total nitrogen (up to 60\%) irrespective of applied configuration.

2. The configurations with SSVF beds as a first stage of treatment were characterized by higher nitrogen removal rate in comparison to configuration with SSHF beds in front.

3. The case study of HCW working with the same composition of wastewater revealed that the configuration SS VF + SS HF ensured better removal of pollutants and in consequence better quality of final effluent.

The authors wish to thank Gdańsk Water Utilities participating in the project entitled "Interactive Water Management" with the acronym "IWAMA" co-funded by BSR INTERREG Programme 2014-2020, within which this paper is written.

\section{References}

1. C. Pelissari, C. Ávila, C. M. Trein, J. García, R. Dultra de Armas, P. H. Sezerino, Sci. Total Environ. 574 (2017)

2. M. Gajewska, H. Obarska-Pempkowiak, Environ. Prot. Eng. 37 (2011)

3. M. Gajewska, A. Tuszyńska, H. Obarska-Pempkowiak, Pol. J. Environ. Stud. 13, 3 (2004)

4. R. H. Kadlec, S. Wallace, Treatment wetlands, second edition (CRC Press Taylor \& Francis Group, Boca Raton, London, New York, 2009)

5. F. Masi, S. Caffaz, A. Ghrabi, Water Sci. Technol. 67, 7 (2013)

6. P. Molle, S. Prost-Boucle, A. Lienard, Ecol. Eng. 34 (2008)

7. F. Masi, N. Martinuzzi, R. Bresciani, L. Giovanelli, G. Conte, Water Sci. Technol., 3 (2007)

8. American Public Health Association (APHA), Standard methods for the examination of water and wastewater (21st Ed. Washington, DC, 2005)

9. Polish standards according limits for discharged sewage and environmental protection from July, 242006 (No. 137, item 984) and January, 282009 (No. 27, item 169).

10. M. Gajewska, K. Jóźwiakowski, A. Ghrabi, F. Masi, Environ. Sci. Pollut. Res. 22 (2015) 
11. K. Miksch, J. Sikora, Biotechnologia ścieków (Biotechnology of wastewater) (Wydawnictwo Naukowe PWN Warszawa, 2010)

12. J. Vymazal, Ecol. Eng. 25 (2005)

13. J. Zhai, Md. H. Rahaman, X. Chen, H. Xiao, K. Liao, X. Li, C. Duan, B. Zhang, G. Tao, Y. John, J. Vymazal, Ecol. Eng. 97 (2016)

14. Y. Millot, S. Troesch, D. Esser, P. Molle, A. Morvannou, R. Gourdon, D. P. L. Rousseau, Ecol. Eng. 97 (2016)

15. A. Morvannou, N. Forquet, S. Michel, S. Troesch, P. Molle, Water Sci. Technol. 71, 9 (2015)

16. J. Paing, A. Guilbert, V. Gagnon, F. Chazarenc, Ecol. Eng. 80 (2015) 